\title{
¿Quién mató a Rosendo? Vanguardia, literatura popular e interlocución obrera
}

\author{
Celina Fernanda Ballón Patti ${ }^{1}$
}

Resumen. Nuestro trabajo se propone analizar la investigación ¿Quién mató a Rosendo?, publicada por Rodolfo Walsh en el Semanario CGT. La misma consta de una serie de siete notas publicadas entre mayo y junio de 1968 y una última nota publicada en mayo de 1969, que tienen por tema el asesinato de dos militantes de base antiburocráticos, y de un jerarca de la burocracia sindical, luego de un altercado grupal que terminó en balacera. Nuestro objetivo es indagar cómo impactó la interlocución obrera en la forma en que Walsh dio cuenta de los hechos y en su manera de pensar la literatura. En este sentido, leeremos estas notas en el marco del debate acerca de la legitimidad de formas y modelos literarios que tuvo lugar en América Latina durante la década del '60. Centraremos nuestro análisis en las distintas conceptualizaciones acerca de la crisis de la novela y en las ideas acerca del testimonio y la literatura popular, tal como Walsh las elaboró a lo largo de las décadas de los 60 y 70.

Palabras clave: Rodolfo Walsh; Semanario CGT; factografía; literatura popular.

\section{[en] "Who Killed Rosendo?”: Vanguard, Popular Literature and Dialogue with the Working Class}

\begin{abstract}
Our research proposes to analyse the investigation ¿Quién mató a Rosendo? (Who Killed Rosendo?), published by Rodolfo Walsh in the weekly paper Semanario CGT (a publication run not by the CGT but by the CGT de los Argentinos). The investigation comprises a series of articles published between May and June of 1968, and one last article published in May of 1969, all of which address the murder of two anti-bureaucratic rank-and-file militants and a hierarch of the union bureaucracy after a group altercation that ended in a shoot-out. Our aim is to unravel the way in which the dialogue with the working class influenced the way Walsh approached his literature and how he recounted events. We will thus be framing these articles within the context of the debate over the legitimacy of literary styles and standards that unfolded in Latin America during the ' $60 \mathrm{~s}$. Our analysis will focus on the different views regarding the crisis of the novel, as well as the ideas on popular testimony and literature as conceived by Walsh throughout the ' $60 \mathrm{~s}$ and '70s.
\end{abstract}

Keywords: Rodolfo Walsh; Semanario CGT; factography; popular literature.

Sumario. 1. Introducción. 2. Semanario CGT: la problemática legitimidad de un portavoz. 3. Literatura y sectores populares: tradición y líneas de fuerza de un debate epocal. 4. Crisis de la novela, factografía y documento: un debate que vuelve. 5. ¿Quién mató a Rosendo?: la novela bajo la montaña de periódico. 6. Linajes de la serialidad: la prensa diaria y el folletín. 7. Del recordatorio a la interpelación: el problemático camino del suspenso. 8. Palabras finales.

Cómo citar: Ballón Patti, C. F. (2020) ¿Quién mató a Rosendo? Vanguardia, literatura popular e interlocución obrera, en Anales de Literatua Hispanoamericana 49, 53-65.

\section{Introducción}

Este trabajo pretende ser un aporte al estudio de un fenómeno político-cultural clave en la Argentina de los años 60: la confluencia de vanguardias sindicales, políticas y culturales. Dicho fenómeno encuentra en la CGT de los Argentinos ${ }^{2}$ uno de sus exponentes más claros. La nueva identidad combativa que encarnaba esta

\footnotetext{
${ }^{1}$ Universidad de Buenos Aires. Buenos Aires. Argentina.

E-mail: celinaballon@yahoo.com.ar

Este trabajo es parte del Proyecto de Investigación Plurianual "La legitimación del escritor moderno en América Latina y Europa. Polémicas, operaciones, representaciones" (CONICET /UBA).

${ }^{2}$ La CGT de los Argentinos (CGTA) surgió como producto de la fractura que se produjo en la Confederación General del Trabajo (CGT) a fines de marzo de 1968. Estuvo integrada por gremios políticamente combativos que se enfrentaron a la dictadura del general Juan Carlos Onganía y a la
} 
central sindical se diferenciaba del sindicalismo peronista tradicional por su estrategia de lucha frentista, que incluía la incorporación a sus filas de universitarios, intelectuales, artistas y curas del recién creado Movimiento de Sacerdotes por el Tercer Mundo. La labor de Rodolfo Walsh como director del Semanario CGT, órgano de prensa de la central sindical rebelde, nos parece un objeto de análisis sumamente productivo para dar cuenta de las discusiones que signaron el campo intelectual del período, en tanto su rol de portavoz lo expuso a un intenso debate político con militantes obreros, debate que radicalizó su propio programa de escritura. Su pensamiento político y literario de aquel entonces se expresa en ¿Quién mató a Rosendo?, texto complejo que tensiona todos los géneros que convoca y que se escribe en diálogo con una voz obrera capaz de impugnar el discurso letrado. La escritura de la investigación asume el carácter de una verdadera praxis política, de allí el interés de este objeto de análisis para dar cuenta de las relaciones entre literatura y política en la Argentina de los años 60.

\section{Semanario CGT: la problemática legitimidad de un portavoz}

En 1972, Walsh reflexionaba sobre su experiencia al frente del Semanario CGT en los siguientes términos:

¿Por qué fue posible esta experiencia del periódico en CGT? Fue posible, pero no porque la inventara yo, sino porque los trabajadores argentinos se daban en la CGT rebelde y ellos me dan a mí la oportunidad de poner mi instrumento a su servicio. (Tarsitano 1972: 6)

De acuerdo con sus propias declaraciones, Walsh actuó por mandato de la central sindical rebelde, que le otorgó el rol de portavoz. La primera pregunta que cabe formularse es por qué él: ¿qué credenciales le habilitaron el lugar de portavoz de los sectores sindicales combativos que nucleaba la central?

La participación de Walsh en el Congreso Cultural de La Habana de 1968 — congreso que se pronunció a favor de la incorporación de los intelectuales en la lucha por la liberación- y su paso por Puerta de Hierro —donde Perón le presentó a Raimundo Ongaro - ${ }^{3}$ fueron los hitos que marcaron su ingreso a la central combativa. La relación entre Walsh y la CGTA expresa, en primera instancia, un intercambio de legitimidades. En el marco de una estrategia de lucha frentista, que hacía un llamamiento explícito a los intelectuales, la presencia de un periodista como Walsh no sólo permitía albergar expectativas fundadas en la creación de un órgano de prensa capaz de convertirse en un organizador del movimiento obrero, sino que también establecía la ligazón de la central opositora con el peronismo combativo. (Recordemos que para ese entonces, Operación Masacre [1957] ya era leído como un relato clave para la historia de la Resistencia Peronista).

Si bien la elección de Walsh como portavoz contaba con importantes avales simbólicos, la legitimación de su rol y de su proyecto de prensa sindical resultó muy complicada. La distribución del periódico experimentaba dificultades relacionadas con las discrepancias políticas en el interior de la CGTA. Este no era el único problema de legitimación que enfrentaba el semanario. El proyecto periodístico de Walsh pensaba al periódico como un medio político inspirado en las ideas leninistas acerca de la prensa. El semanario se concebía como un medio de contra-información y organización, cuya densidad informativa planteaba al lector exigencias poco comunes para las publicaciones sindicales tradicionales, limitadas a problemas gremiales particulares o a la difusión de sus servicios. La brecha entre las competencias intelectuales demandadas por textos como los de Walsh y las que efectivamente poseían los lectores creaba considerables problemas de recepción. El resultado fue la sospecha acerca de quién era el verdadero destinatario del mensaje: la voz del "portavoz" parecía hablar en nombre de un grupo distinto de aquel que le había otorgado el mandato, y la legitimidad de su palabra resultaba fácilmente erosionada. La estrategia del periódico consistió en la publicación de los debates sostenidos en la central sindical y en el llamamiento a los lectores a asumir el rol de corresponsales obreros. Pero las tensiones que dificultaban la legitimación del rol de Walsh en tanto portavoz de los militantes obreros eran mucho más profundas de lo que podía sugerir el análisis de lo publicado por el semanario. Las declaraciones de Raimundo Ongaro luego de leer Un kilo de

conducción del máximo dirigente de la burocracia sindical de la época: Augusto Timoteo Vandor, cuya táctica de negociación con el gobierno de facto había propiciado un serio retroceso en las conquistas del movimiento obrero. El programa de la CGTA fue pluralista, antiimperialista, partidario de una reconstrucción sindical desde las bases y promotor de iniciativas que coordinaron distintas luchas sociales y políticas. La vida institucional de esta central sindical se desarrolló en un marco de semi-legalidad y duró menos de dos años: a mediados de 1969 fueron encarcelados sus dirigentes y a comienzos de 1970 solo quedaban agrupaciones sindicales clandestinas que tenían graves dificultades para continuar militando en un contexto de creciente represión.

${ }^{3}$ Dirigente sindical que estuvo al frente de la CGT de los Argentinos desde su fundación. Fue elegido Secretario General de la CGT en el Congreso Normalizador "Amado Olmos". La negativa de los gremios vandoristas y participacionistas a aceptar el triunfo de Ongaro ocasionó la ruptura. 
oro (1967) fueron lapidarias. Así las registra Walsh en su diario personal: "No entiendo nada", parece que dijo Raimundo. “¿Escribe para los burgueses?”(Walsh 1996: 133).

\section{Literatura y sectores populares: tradición y líneas de fuerza de un debate epocal}

La acusación de "escribir para los burgueses" llevaría a Walsh a replantearse a fondo su propia producción literaria. Porque a pesar de lo dolorosa que resulta la crítica, no puede dejar de reconocer que Ongaro está en lo cierto: "Cosa que me molestó lo que dijo Raimundo, que yo escribía para los burgueses. Pero me molestó porque yo sé que tiene razón, o que puede tenerla" (Walsh 1996: 135). Inmediatamente después de asumir la crítica, Walsh se pregunta:

¿Pero qué es lo más específicamente burgués de lo que yo escribo, lo que más molesta a Raimundo? Creo que puede ser la condensación y el símbolo, la reserva, la anfibología, el guiño permanente al lector culto y entendido. [...] Otra cosa que puede -debería- molestarle: la traslación burguesa de un personaje popular, como el de "Corso". (Walsh 1996: 134)

En estas anotaciones, hechas en 1969, Walsh identifica un objetivo: "agarrarlos a ellos como tema, sus vidas, su lucha" y dos primeros problemas a resolver: los relacionados con el preciosismo formal, al que Walsh se referiría más tarde como a una "aventura del lenguaje", y las dificultades que implica dar cuenta de los sectores populares en términos que no sean los hegemónicos, vale decir, los de su enemigo. La literatura debe enfrentarse a dos desafíos muy diferentes: renunciar a la experimentación formal -cuyos resultados, para ser descifrados, exigen competencias culturales de las que carecen los nuevos destinatarios- y construir nuevas narrativas que den cuenta de los sectores populares sin traicionarlos. Lo cual, por supuesto, implica reconfigurar el habitus (Bourdieu 1991) profesional y de clase con el que se mira al otro antes de dar cuenta de él. La tarea es compleja: "Todo esto equivale a aprender de nuevo multitud de cosas" (Walsh 1996: 151).

Este aprendizaje del que habla Walsh comienza, como todos, con un reconocimiento de la ignorancia: "La cosa es: ¿para quién escribir, si no es para los burgueses? Tendría que preguntarle a Raimundo qué literatura le gusta a él, qué novelas no están escritas para los burgueses y qué cuentos pueden escribirse 'para' los obreros" (Walsh 1996: 133). En principio, el diagnóstico es pesimista: el autor considera que el mundo de los libros está cerrado a los obreros y que los mismos escritores se han encargado de que así sea. Las referencias a los novelistas identificados con la literatura popular es escasa: aparecen al pasar los nombres de Pío Baroja, Roberto Arlt y Eduardo Gutiérrez.

La relación que Walsh establece con el legado de estos escritores es problemática. No se extiende demasiado acerca de él en su diario, pero en lo poco que dice a lo largo del tiempo se traslucen las tensiones. El juicio de valor más temprano que encontramos es acerca de Roberto Arlt: "Me gustaría tener su fuerza, su resentimiento, su capacidad dramática, su decisión de enfrentar a los personajes [...] pero no me gustaría escribir una sola de sus líneas" (Walsh 1996: 89). El juicio sobre Baroja —un poco posterior- es lapidario: lo define como "panadero". De Eduardo Gutiérrez sólo dice que es un modelo preferible a Paul Groussac.

Más allá de las diferencias que separan a estos tres autores, se impone un rasgo común: la fuerte impronta del folletín en sus obras. Walsh no menciona explícitamente la novela por entregas hasta que escribe las notas en el Semanario CGT. La incorporación de los narradores obreros en las notas acerca del tiroteo le permite al autor esbozar su visión de la relación que los militantes de base entablan con la literatura. Así relata Raimundo Villaflor lo sucedido cuando se perdió la huelga que encabezó: "Pero resulta que adentro de la fábrica me estaba esperando el principal Plomer. Estuvo allí toda la noche, era mi sombra negra, igual que el policía ese que persigue a Jean Valjean en Los Miserables, ¿cómo se llamaba?” (Walsh 1968a: 6). La voz del narrador nos deja entrever una relación discontinua con el libro: Villaflor no recuerda el nombre del antagonista. Por otro lado, se advierte la gravitación de un motivo clásico en la literatura popular: la denuncia del aparato judicial como instrumento de persecución de los sectores subalternos (Gramsci 1998).

Posteriormente, Walsh replantea el posible linaje de la novela futura, aquella que escribirá luego de haber escrito la "novela burguesa", y reconoce que tanto Arlt como Gutiérrez podrían ser influencias válidas: "Una novela, vgr., que empiece con una declaración franca de principios políticos, brutal en la mención de nombres y personas, simple en su lectura (cf. Eduardo Gutiérrez, Arlt)" (Walsh 1996: 157). Llamativamente, no hay ninguna referencia al policial, género popular por excelencia.

Este nuevo modo de considerar la tradición literaria popular no puede pasarse por alto. Las reflexiones acerca del vínculo que los sectores subalternos mantienen con la literatura tienen por referencia ineludible la puesta en cuestión de la legitimidad de las formaciones culturales burguesas. Por lo tanto, la cuestión de la legitimidad del escritor en tanto portavoz no puede disociarse de la legitimidad de las formas literarias que 
asume la representación. En este caso concreto, se trata del debate acerca del fin de la novela. En un reportaje concedido a Ricardo Piglia en marzo de 1970, Walsh se explaya al respecto:

Habría que ver hasta qué punto el cuento, la ficción y la novela no son de por sí el arte literario correspondiente a una determinada clase social en un determinado período de desarrollo y en ese sentido y solamente en ese sentido es probable que el arte de ficción esté alcanzando su esplendoroso final, esplendoroso como todos los finales, en el sentido probable que un nuevo tipo de sociedad y nuevas formas de producción exijan un nuevo tipo de arte más documental, mucho más atenido a lo que es mostrable. (Walsh 1996: 218)

Walsh reconoce la gravitación que ejercen sobre los escritores ya consagrados las categorías burguesas que postulan a la novela como obra cumbre de la literatura, pero se muestra esperanzado de que las nuevas generaciones formadas en países no capitalistas o en países en proceso de revolución acepten el estatuto artístico de la denuncia y el testimonio. En definitiva, apuesta por una renovación de los géneros en el que periodismo y literatura son vasos comunicantes: "Es decir, evidentemente, en el montaje, la compaginación, en la selección, en el trabajo de investigación, se abren inmensas posibilidades artísticas" (Walsh 1996: 219). Un año antes, ante un periodista de la revista Siete Días, había esbozado ideas similares:

Yo creo que sí puedo escribir una novela, pero lo que está en crisis -al menos en lo que a mí atañees el concepto mismo de novela. Es decir, toda la novela, lo que podríamos llamar las relaciones falsas del género como tal. [...] En el plano técnico, de realización, lo que más me molesta son las falsas articulaciones de la novela tradicional, sus convencionalismos. [...] Más que la continuidad de los personajes, me interesa la continuidad de ciertas situaciones históricas. (Walsh 1996: 118119)

En esta misma entrevista, Walsh establece una diferencia clave entre la novela y la literatura documental: "De alguna manera, una novela sería algo así como una representación de los hechos, y yo prefiero su simple presentación" (Walsh 1996: 118).

\section{Crisis de la novela, factografía y documento: un debate que vuelve}

Las consideraciones de Walsh revelan importantes similitudes con las ideas expresadas por Walter Benjamin en "El autor como productor". En este texto, el filósofo alemán señala que "no siempre hubo novelas en el pasado, y no siempre tendrá que haberlas" (Benjamin 1975: 120), que lo mismo vale para la tragedia y la épica; y que las formas del comentario, la traducción e incluso la falsificación no siempre han sido marginales en la literatura. Géneros y jerarquías son históricos y Benjamin considera, a mediados de la década del 30, que éstos se hallan en proceso de refundición. Sergei Tretiakov desarrolla la reflexión y acuña el concepto de "factografía" para dar cuenta de un nuevo procedimiento artístico centrado en el montaje de los documentos. La función del autor factográfico, puntualiza Víctor del Río, "pasará a ser la de buscador, compilador y montador de hechos y, en el caso de los factógrafos más radicales como Tretiakov, parte de la estructura productiva en tanto que "escritores operantes"” (Del Río 2010: 33).

Esta frase resume un conjunto de problemáticas que creemos vale la pena desglosar. A fin de dar cuenta de los postulados y objetivos del movimiento factográfico, consideramos imprescindible el análisis de los textos en los que los fundadores abordan problemáticas tales como la caducidad de la literatura de ficción en particular, de la novela-, la metamorfosis de los géneros literarios, el rol político del escritor y las características del montaje que proponen.

La crisis histórica de la literatura de ficción es tematizada tanto por Nikolai Chuzhak como por Sergei Tretiakov. El primero de ellos reconoce que la literatura de ficción resultó en el pasado históricamente indispensable y socialmente funcional. En una época en que la investigación científica y la prensa eran muy rudimentarias, los activistas sociales se volcaban a la literatura a fin de construir representaciones del mundo. La elección de la literatura se justificaba, según Chuzhak, tanto por la falta de mejores herramientas que pudieran cumplir con este objetivo, como por ciertas características que el teórico considera inherentes a la ficción (el simbolismo brumoso, ser poco concluyente, su relación con el universo de la fábula, la arbitrariedad de sus construcciones), que la harían menos vulnerable a la censura política. La falta de cualquier tipo de liderazgo político colectivo generó la demanda de un creador individual, cuya tarea era no sólo acopiar y registrar los hechos esenciales de la vida, sino también usar lo que según Chuzhak eran "sus 
ideas previas intuitivas" para transformar y generalizar el material. El creador era reconocido por los demás "como un chamán, o mejor dicho, como un maestro de vida" (Chuzhak 2006: 83). La expansión del conocimiento científico y de la esfera pública, así como el surgimiento de una nueva capa de jóvenes administradores, originaron nuevos lenguajes privilegiados para dar cuenta del mundo y nuevos agentes capacitados para llevar a cabo dicha tarea. El rol del creador como conocedor se ha vuelto anacrónico. En palabras de Tretiakov: "The space of the writer's problematic only keeps getting narrower -just a bit more and there will be nothing more for the writer as teacher to do" (Tretiakov 2006a: 48). Desprovista ya de su antigua función social, la literatura de ficción adquiere todos los rasgos del fetiche. Tanto Chuzhak como Brik consideran que su función es construir una vía de escape de las condiciones materiales de existencia. La literatura deviene, por lo tanto, un agente de alienación que pone el mundo de revés:

L'intelliguentsia russe qui pendant de nombreuses années a été à l'écart et dans l'ignorance de tout travail pratique, a poussé jusqu'à la plus immense virtuosité l'art de vivre émotionnellement des faits et des événements imaginaires. Et inversement elle a appris à se comporter envers les faits comme envers la fiction. (Brik 1987a: 184)

Chuzhak lo afirma del modo más categórico posible: "Belles lettres is opium for the people" (Chuzhak 2016: 94).

El blanco por excelencia de las críticas de la factografía es la novela, en tanto gira alrededor de un héroe, cuyos conflictos constituyen el eje de una trama. En torno a los personajes principales se disponen los personajes secundarios, que funcionan como satélites de los protagonistas. Así describía Lukács este principio de construcción de la novela: “[...] se individualiza a los personajes por su posición social ante problemas abstractos, la fisonomía intelectual es también aquí el medio principal de la plasmación de la personalidad viva" (Lukács 1966: 126).

Tretiakov encuentra en los principios constructivos de la novela la expresión más clara de la filosofía idealista que afirma que el hombre es la medida de todas las cosas. Su juicio es terminante: al novelista clásico no le interesa la persona en tanto partícipe del proceso económico (lo cual se debe, según él, a que el arte idealista aún conserva sus raíces feudales, que postulan al rentista como figura predominante):

Heroics engineers, doctors and financiers do exist in the novel, but typically only a minimal number of lines are given to what they do and how they do it. But then again, the novel has a lot to say about how they kiss, how they eat, how they enjoy themselves, how they languish and how they die. (Tretiakov 2006c: 59)

Los conflictos que enfrenta el héroe son primordialmente de carácter psicológico: los personajes de la novela han sido apartados del mundo de la producción y trasladados a los sistemas de relaciones de la vida cotidiana. El peso del mundo objetivo es insignificante en relación al del mundo subjetivo. El resultado de ello es que el héroe devora y subjetiviza toda la realidad:

The Onegins, Rudins, Kararamazovs and Bezukhovs are the suns of independent planetary systems around which characters, ideas, objects, and historical processes orbit submissively. More accurately, they aren't even suns, but just common planets that have mistaken themselves for suns and have not yet come into contact with a Copernicus who will put them in their place. (Tretiakov 2006c: 59)

La factografía considera imprescindible una ruptura radical con la literatura decimonónica. En primer lugar, porque las exigencias de la trama narrativa ficcional conllevan una selección que termina por desvirtuar los hechos. En palabras de Ossip Brik: "Toute construction centrée sur un sujet viole obligatoirement le matériau, en prenant de lui seulement ce qui peut servir au développement de la trame narrative, et déforme pour les mêmes raisons les éléments ainsi choisis" (Brik 1987c: 189). Por si hicieran falta aclaraciones, Brik recuerda en otro de sus textos que los factógrafos tienen demasiado respeto por los hechos asociados a la memoria de Lenin para permitir que fueran deformados por consideraciones literarias: la autenticidad no admite licencias.

La segunda de las razones tiene que ver con la temporalidad revolucionaria: los cambios son demasiado rápidos para ser captados por una novela, que requiere un tiempo de producción demasiado extenso. Cuando la novela ha sido terminada, los hechos ya son otros. La tercera de las razones tiene que ver con las expectativas asociadas a cada género en particular. La novela, en tanto género, posee una fuerza gravitatoria 
que orienta la lectura en función de sus propios esquemas ficcionales, trazando así un horizonte del que no se puede escapar ni siquiera cuando se la aborda de manera vanguardista:

The power of the novel's canon is so great that every professional moment is perceived as an annoying digression from the novel's usual plot, and every piece of physiological information is regarded either as a symptom of a psychological experience or a tedious diversion from the reader's attention. (Tretiakov 2006c: 60)

La factografía opone a esta literatura de ficción una literatura documental que se propone reafirmar los hechos. Su foco no está puesto en las experiencias emocionales, sino en la organización de la sociedad. A la hora de definir el método, Tretiakov señala tres aspectos decisivos. El primero es la investigación de los hechos en su especificidad y en sus manifestaciones concretas. El segundo es el procesamiento periodístico del material documental. Tretiakov marca varios objetivos: extraer la cadena dialéctica de la cual el hecho es el eslabón decisivo, dotarlo de eficacia para la agitación, poner a prueba su público, interés social y significación. El hecho debe convertirse en un argumento, una señal, una propuesta concreta. El tercero consiste en las conclusiones prácticas: operacionalizar las producciones literarias a fin de que contribuyan a la reorganización de la realidad de acuerdo con el socialismo. En este último punto, la literatura será medida con la vara de la eficacia. Las obras factográficas deberán demostrar que pueden ser herramientas análogas a los desarrollos de la ciencia (ya no se reconoce una frontera entre ciencia y literatura, puesto que ambas responden a los mismos objetivos). La literatura ha perdido su antigua primacía. Los discursos sociales privilegiados son otros, aquellos que pueden brindar soluciones a los problemas más acuciantes del presente. Tretiakov es claro al respecto: "The most interesting books turn out to be those that are written by doctors, travelers, politicians, technicians -in a word, people whose trade is anything except literature" (Tretiakov 2006b:54).

La literatura factográfica es una literatura de carácter descriptivo, sin sujeto y sin intriga, cuyo argumento ya no estará dado por los avatares del destino del héroe, sino por las relaciones dialécticas que los hechos mantienen entre sí. Privilegia géneros considerados "menores" tales como el reportaje, la monografía, las biografías, los relatos de viajes, el folletín, las memorias, los informes, el panfleto y la investigación periodística. Esta última, en particular, resulta clave para el desarrollo del proyecto factográfico: según Tretiakov, los periódicos son para el activista político soviético lo que la novela didáctica era para el cristiano medieval: una guía para todas las situaciones de la vida, debido a que las publicaciones periódicas engloban los acontecimientos, su síntesis y las directivas en todos los frentes de la sociedad. La velocidad a la que la prensa incorpora los hechos y su llegada a las masas son factores fundamentales para otorgarle una relevancia de primer orden: "If we were to compare the print runs of newspapers with those of so-called 'elegant literature' both in Tolstoy's time and today, we would clearly see that belles lettres have been crushed by a mountain of newspaper" (Tretiakov 2016: 49).

\section{5. ¿Quién mató a Rosendo?: la novela bajo la montaña de periódico}

Resulta imprescindible señalar un fenómeno que en ocasiones se ha pasado por alto: las consideraciones teóricas de Walsh no cristalizan en respuestas definitivas. La idea de escribir una novela hecha de cuentos que retomarían personajes y situaciones de Los oficios terrestres (1965) y Un kilo de oro (1967) también estaba presente en Walsh al momento de reflexionar sobre el posible final de la novela burguesa y el advenimiento de la literatura de testimonio. Una entrevista concedida a Ricardo Piglia muestra claramente estas contradicciones. En un párrafo de la misma, Walsh admite adherir a la jerarquía tradicional del campo literario: "[...] me he criado dentro de esa concepción burguesa de las categorías artísticas y me resulta difícil convencerme de que la novela no es en el fondo una forma artística superior" (Walsh 1996: 219). En esta misma entrevista, dice también que "esa novela que uno quiso escribir desde los 15 años no sirve para un carajo y en realidad lo que hay que escribir es otra cosa" (Walsh 1996: 224). Todo está permanentemente en cuestión en su pensamiento de aquél entonces: el canon novelístico, el periodismo, la literatura popular. Es por eso que consideramos particularmente relevante el análisis de las notas sobre el tiroteo de la confitería La Real publicadas en el Semanario CGT: creemos que ciertas respuestas sólo las brinda el proceso mismo de la escritura.

La crítica literaria tradicional podría cuestionar la pertinencia de analizar unas notas de prensa publicadas en un periódico sindical como exponentes de un debate epocal acerca de los géneros literarios y de la propia posición de un escritor con una reconocida obra ficcional, pero el abordaje teórico factográfico nos señala 
que es justamente allí donde deben indagarse las tensiones más relevantes de la discusión. Otros abordajes teóricos también nos ponen sobre la misma pista. En su ensayo "Estructura del 'suceso" Roland Barthes introduce una distinción que nos parece fundamental:

Ha ocurrido un asesinato: si es político, es una información, si no lo es es un suceso. [...] Esta diferencia aparece inmediatamente cuando se comparan nuestros dos asesinatos; en el primero (el asesinato político), el hecho (el crimen) remite necesariamente a una situación extensiva que existe al margen de él, antes que él y en torno a él: la 'política'; aquí la información, no puede comprenderse inmediatamente, sólo puede definirse en proporción a un conocimiento exterior al hecho, que es el conocimiento político, por confuso que sea; en resumen, el asesinato escapa al suceso siempre que es exógeno, procedente de un mundo ya conocido, en este caso podemos decir que carece de estructura propia, suficiente, ya que es siempre el término manifiesto de una estructura implícita que le es preexistente: no hay información política sin duración, ya que la política es una categoría transtemporal, por otra parte, ocurre lo mismo con todas las noticias procedentes de un horizonte nombrado, de un tiempo anterior: nunca pueden constituir sucesos; literariamente son fragmentos de novelas. (Barthes 2003: 259-260)

En el mismo momento en que reflexiona acerca del posible fin de la novela, Walsh - en tanto narrador-se enfrenta a la tarea de insertar la investigación sobre el tiroteo de La Real en el macrorrelato de la política nacional. La historia de la investigación de los asesinatos -por lo tanto- puede leerse también como la historia de la problemática construcción de la novela.

El caso que nos ocupa presenta algunas características fundamentales que tornan dicha construcción particularmente difícil. En primer lugar, la nula relevancia política de dichos crímenes al momento en que Walsh escribe su investigación: han pasado dos años del hecho, la investigación está en un punto muerto y la prensa ya no se ocupa del tema. El mismo autor lo reconoce en el primer apartado de la primera nota:

El asombro, la indignación, las versiones, los alegatos, se diluyeron a lo largo de las semanas, los meses. Hoy son pocos, fuera de Avellaneda, los que se acuerdan de la muerte de Rosendo García. Casi nadie de Domingo Blajakis y Juan Salazar, sepultados oscuramente, sin carrozas, sin discursos, sin más compañías que los familiares y unos pocos fieles. (Walsh 1968a: 2) ${ }^{4}$

Esta rápida caducidad de la noticia era previsible: los principales diarios del país narraron los crímenes como si fueran sucesos. Al publicar la investigación en forma de libro, Walsh postularía las razones de la manera en que los medios narraron los hechos:

Cinco días después del episodio de Avellaneda, La Prensa había publicado un editorial titulado "Entre Ellos", que exhalaba ese odio inconfundible, a veces cómico, que profesa contra la clase trabajadora en general. [...] El silencio que rodeó a esta campaña [Walsh se refiere aquí a la investigación publicada por Semanario CGT] prueba que el interés real de ese periodismo era mantener el misterio que borraba las diferencias "entre ellos". Cuando resultó que "entre ellos" no estaban solamente "algunos dirigentes gremiales adictos a la tiranía depuesta", sino la policía, los jueces, el régimen entero, el desagradable asunto volvió al olvido. (Walsh 2003: 8-9)

Otra de las aristas fundamentales de esta dificultad es el capital social y político de dos de los tres muertos en el tiroteo. Walsh señala esto muy agudamente en el prefacio del libro: "Para los diarios, para la policía, para los jueces, esta gente no tiene historia, tiene prontuario" (Walsh 2003: 7). Restituirles la historia a las víctimas es un requisito indispensable para inscribir lo sucedido en el macrorrelato de la política argentina. En una nota al pie, señala Roland Barthes: "En cierto sentido, es adecuado decir que la política es una novela, es decir, un relato que dura, a condición de personificar a sus actores" (Barthes 2003: 260).

La lectura de la investigación evidencia cuán seriamente asumía Walsh esta necesidad de personificar a los actores. Las notas del semanario incluyen la biografía de cada uno de los militantes de base involucrados en el hecho. Tres de ellas nos parecen particularmente relevantes para indagar el paradigma bajo el cual se

\footnotetext{
${ }^{4}$ Walsh modifica la grafía de estos apellidos a lo largo de la investigación: comienza escribiendo "Blajakis" y "Salazar" y luego los registra como "Blajaquis" y "Zalazar".
} 
construyen los personajes: la de Domingo Blajaquis, la de Juan Zalazar y la de Rolando Villaflor. Creemos que en estos tres casos estamos ante lo que Lukács llamaba personajes típicos: aquellos cuya vida concentra en grado máximo las contradicciones sociales de un período histórico: "La figura poética sólo puede ser significativa y típica cuando el artista logra poner al descubierto los enlaces múltiples entre los rasgos individuales de sus héroes y los problemas objetivos generales de la época” (Lukács 1966: 130).

En el caso de Blajaquis, se trata del luchador popular por antonomasia: su vida entera es testimonio de la lucha sin cuartel de las bases y de las traiciones de la dirigencia político-sindical. Walsh construye una figura heroica que termina cobrando ribetes míticos:

[...] porque todos sabían que Domingo Blajaquis había estado preso tal vez desde que nació, y que era el primer hombre que sufrió la Picana, tal vez el inventor del Gran Sufrimiento de la Picana, que la policía siempre los buscó y que él contestó a la policía y a todos los explotadores del mundo con bombas que hacían saltar los puentes y las fábricas de los explotadores. Así crecía el mito. (Walsh 1968g: 6)

En el caso de Zalazar, estamos ante la otra cara de la moneda: si Blajaquis simboliza la lucha de la clase obrera, Zalazar representa su pobreza y su sufrimiento. Walsh explicitaría la tipicidad de ambos personajes al publicar la investigación como libro: "Ese hombre, el Griego Blajaquis, era un auténtico héroe de su clase. A mansalva fue baleado otro hombre, Zalazar, cuya humildad y cuya desesperanza eran tan insondables que resulta como un espejo de la desgracia obrera" (Walsh 2003: 7). La vida de Zalazar es una sucesión de infortunios que expresan en grado máximo el drama de la clase obrera argentina. Si Blajaquis es un héroe, Zalazar es un mártir.

La tercera semblanza es la que resulta más compleja de analizar, y la que llevaría a Walsh a interrogarse acerca de los límites del testimonio. Se trata de Rolando Villaflor, ex ladrón con condena cumplida por asalto en banda. La militancia política es un camino de redención para el menor de los hermanos Villaflor: "A través de la acción política, Rolando Villaflor hizo un tratamiento heroico. [...] El suyo había sido el camino más duro" (Walsh 1968c: 6). Narrar la biografía del menor de los Villaflor resultaba coherente con uno de los objetivos que Walsh enunciaría un tiempo más tarde en un breve apartado de su diario personal titulado "Teoría General de la Novela": "Trazar el avance de los héroes, desde la resignación hasta el triunfo que se sabe no-definitivo" (Walsh 1996: 150-151). La indignación de la familia Villaflor lo confronta con una arista que hasta entonces había pasado por alto: el género testimonial implica todo un sistema propio de tensiones entre historia y relato cuya primera consecuencia es la construcción de un régimen de lo decible. En su diario personal, escribe lo siguiente:

[...] si yo persigo ciertos fines políticos inmediatos, ${ }^{5}$ tengo que dar una verdad recortada, no puedo ofender a mis amigos que son mis personajes: recuerdo la reacción de R. y su familia cuando conté su pasado de asaltante. (Walsh 1996: 186-187)

La frase resulta reveladora en tanto señala la necesidad de elaborar esas vidas en términos coherentes con los paradigmas del relato que da cuenta de ellas. Puestos sobre el papel, esos seres de carne y hueso son personajes que deben cumplir un rol en la estructura del relato. Creemos que Walsh reveló el pasado del menor de los Villaflor porque era funcional a la construcción del mosaico de la clase obrera combativa que construye el libro. Rolando Villaflor encarna un arquetipo de larga vida en la literatura popular: aquél que se pasa al bando correcto. La figura del tránsfuga es insoslayable y en el caso argentino, cuenta con un exponente tan relevante como el Sargento Cruz. Es comprensible que Walsh no quisiera renunciar a la eficacia retórica que tendría la revelación de esta historia de vida "non sancta". La conversión de Rolando se sintetiza con una frase - "Un hombre nace de nuevo"- que nos parece sumamente relevante, en tanto da cuenta de la influencia de los arquetipos del folletín en la escritura de esta semblanza.

Quedan dos personajes que no llegan a constituirse en tipos, pero cuya biografía resulta pertinente en tanto expresa dos mitos del peronismo: en el caso de Raimundo Villaflor, se trata de la lucha de la Resistencia, en el caso de Francisco Granato, se trata del rol de Eva Perón como benefactora de los humildes.

${ }^{5}$ Aquí figura una anotación tachada a mano en el original: "no puedo decir todo". 
En todos los casos, la vida de los personajes se presenta como signada en todos sus aspectos por las determinaciones de la clase social y la lucha política. La semblanza biográfica de Granato lo deja en claro: "Después ella [Eva Perón] se murió. Después Francisco Granato cambió de trabajo. Después cayó Perón. La infancia había concluido" (Walsh 1968e: 6).

\section{Linajes de la serialidad: la prensa diaria y el folletín}

A fin de dar cuenta del modo en que el relato acerca del tiroteo de La Real se narra en forma de novela, nos parece particularmente pertinente el concepto de "folletín mediático", tal como lo desarrollan Françoise Revaz, Stéphanie Pahud y Raphaël Baroni (2007). Esta categoría da cuenta de un fenómeno que nos parece particularmente digno de considerar: el hecho de que los relatos periodísticos que se desarrollan en episodios sucesivos se organizan - desde el punto de vista narratológico - de un modo similar a los folletines. Aquello que unifica a ambos es un mismo tipo de tensión narrativa. Dicha tensión se caracteriza, en primer lugar, por ser intermitente, ya que está estructurada por una narración discontinua, interrumpida al final de cada episodio. Esta fragmentación impone una actualización a lo largo del tiempo. Ambos tipos de relatos comparten procedimientos narrativos que se caracterizan por una diégesis episódica reticente. El interés de los mismos se funda en lagunas informativas que resultan de la interacción entre dos temporalidades: la de la acción y la del relato. Y en ambos casos, se trata de relatos que -concebidos como actos comunicativos- no aparecen como productos sino como procesos.

El suspenso y la curiosidad característicos de ambos folletines presentan sin embargo importantes diferencias. En lo que refiere a la curiosidad, el folletín mediático puede terminar antes de que se haya develado la causa: una caída en el interés del público basta para que el relato quede trunco. En el caso del suspenso, el interés se funda en el desarrollo cronológico de un evento incompleto que nos lleva a interrogarnos acerca de su desarrollo posterior y a elaborar un pronóstico cuyo carácter incierto genera una emoción que se asemeja a la tensión narrativa. Revaz, Pahud y Baroni señalan que es este el momento en el que la prensa se hace política, porque se proyecta hacia un futuro que todavía puede ser transformado.

Consideramos pertinente señalar otra diferencia: en los folletines mediáticos suele prevalecer una de estas dos formas de la intriga, según se trate de acontecimientos finalizados o acontecimientos en curso. Todorov señala que existe un relato ficcional que conjuga ambos tipos de intriga: la novela de suspenso:

De la novela de enigma, la novela de suspenso conserva el misterio y las dos historias, la del pasado y la del presente, pero rechaza reducir la segunda a un simple descubrimiento de la verdad. Como en la novela negra, es la segunda historia la que ocupa el lugar central. El lector está interesado no sólo por lo que ha ocurrido sino también por lo que va a ocurrir más adelante, se interroga tanto sobre el porvenir como sobre el pasado.[...] El misterio tiene una función diferente de la que desempeñaba en la novela de enigma: es, primordialmente, un punto de partida; el interés principal reside en la segunda historia, la que se desarrolla en el presente. (Todorov 1992: 50)

¿Puede un folletín mediático organizarse de modo análogo a una novela de suspenso? El análisis de ¿Quién mató a Rosendo? es un buen modo de responder a esta pregunta.

\section{Del recordatorio a la interpelación: el problemático camino del suspenso}

Una lectura somera de las notas basta para advertir que allí se cuentan dos historias: la de los asesinatos y la de la investigación llevada a cabo por Walsh. La primera se narra en pasado, la segunda en un presente acosado por la urgencia. Estamos ante un folletín mediático que se enfrenta a la tarea de conciliar dos temporalidades: la de los hechos y la de su investigación, que parecen en principio invalidarse mutuamente porque ha pasado demasiado tiempo. La estrategia de Walsh para reactualizar el tema - la interpelación a Vandor- resulta indisociable de la táctica política: estamos ante un intento de lograr el reconocimiento público de la CGT de los Argentinos como interlocutor legítimo.

La historia de la investigación de los asesinatos de La Real es indisociable de la polémica que busca entablar el texto. Entendemos polémica en los mismos términos en que lo hace Dominique Garand:

Dans le récit polémique, le malaise éprouvée par le Sujet est associé á un Tort : quelque chose est qui ne devrait pas être. Ce Tort crée des victimes (locuteur ou groupe qui l'inclut ou non) et il a une origine : personne, idéologie, religion, etc., qu'il faut identifier en vue d'une réparation. Le texte 
polémique cherche à identifier le Tort, à le faire reconnaître en tant que tel, à pointer du doigt ses sources, à proposer des solutions (allant jusqu'à l'élimination de la source ou à son discrédit). (Garand 1998: 222)

Vandor no responde los cargos que se le formulan en el periódico, tampoco lo hacen los vandoristas involucrados en el tiroteo. La historia de la investigación se construye como una serie de fracasos en la interlocución polémica que hacen avanzar el relato de los crímenes, ya que redundan en la publicación de los nombres de todos los involucrados que han rehusado la exhortación de Walsh a declarar (que al comienzo de la investigación eran identificados con iniciales o con la letra X). La constatación de este hecho nos pone en la pista de un punto de análisis insoslayable: la complejidad del vínculo entre la historia de los crímenes y la historia de la investigación. Walsh lo señala en la tercera nota: "El relato consustanciado y necesariamente lento que aparece en estas páginas no hará olvidar -espero- el hecho de que hay de por medio un triple homicidio impune, y una investigación en marcha" (Walsh 1968c: 6).

El autor teme que la morosidad de la primera historia sabotee a la segunda, como si el relato pormenorizado de los hechos coartara la posibilidad de narrar la historia de la investigación. Si la segunda historia está en riesgo, es la relevancia de los hechos pasados en el aquí y ahora lo que está en cuestión. Por otra parte, la potencialidad actual del acontecimiento pone en juego la narración de los crímenes, en tanto el autor deja en claro que está dispuesto a no publicar ciertos datos a cambio de la cooperación en el esclarecimiento del caso. La jerarquía de ambas historias queda clara: en cierto momento de la investigación el relato de los crímenes es parcialmente negociable. La narración privilegia el mecanismo del suspenso (orientado al aquí y ahora de la investigación) por sobre la curiosidad (referida a sucesos ocurridos dos años atrás). Esto no implica que la estrategia de la curiosidad no haya sido cuidadosamente trabajada en el texto, al punto de ser satisfecha en el inicio sólo para ser reformulada a continuación. ¿Quién mató a Rosendo? se organiza desde su título como un whodunnit: declara que el punto central de la investigación es descubrir la identidad del asesino. Esta pregunta sin embargo se responde en la primera de las notas: en el apartado "Advertencia" el autor se compromete a probar que todos los disparos partieron del grupo vandorista.

El texto, a primera vista, se estructura de un modo paradójico que aborta su continuidad: la pregunta que formula se responde en el inicio de la investigación. Si ésta continúa es porque el carácter de la pregunta excede al autor del crimen: no estamos en realidad ante un whodunnit, sino ante el relato de un asesinato cuyo objetivo es convertirse en novela: dar cuenta, tal como dice Barthes, de "una situación extensiva que existe al margen de él" (Barthes 2003: 260). Responder el interrogante implica, por lo tanto, dar cuenta de las luchas por el poder al interior del peronismo, de las maniobras mafiosas de la burocracia sindical y del encubrimiento urdido por el aparato judicial del gobierno de facto. Walsh lo deja en claro en la primera nota:

Es probable que en su fuero interno Vandor se haya sentido enfrentado con Perón mucho antes de 1965, y acaso antes de 1959 cuando la huelga de los metalúrgicos escribió una notable página de lucha. No interesa aquí dilucidar el detalle, pero hay que tener en cuenta el hecho si queremos entender la muerte de Rosendo García y el asesinato de Blajakis y Salazar. (Walsh 1968a: 2)

Otro punto que nos interesa esclarecer es si la curiosidad que estructura el relato comporta algún tipo de reticencia propia de los relatos de ficción. Nos parece que la siguiente consideración de Revaz y Baroni sobre el carácter incompleto del folletín mediático es una guía adecuada para este análisis:

Il faut $[\ldots]$ préciser que si l'effet de lecture "suspensif" est comparable, cet effet tient à une incomplétude involontaire de l'auteur de l'article de presse, à une ignorance qu'il partage avec le lecteur, alors que dans la fiction, l'incomplétude relève d'une stratégie d'écriture qui met en jeu une asymétrie épistémique essentielle au fonctionnement de cette littérature. Ce n'est d'ailleurs pas seulement pour des raisons déontologiques que l'auteur d'un article de presse évite de dissimuler son savoir à son lecteur, mais parce que la concurrence acharnée que se livrent les médias d'information fait que l'information tue par l'un serait de toute façon reprise par un autre. (Revaz y Baroni 2007: 196)

La pregunta es, entonces, si Walsh capitalizó la falta de competencia informativa en torno al caso para introducir dilaciones que responden al mecanismo de reticencia propia del texto literario. Nuestro análisis revela que, desde la primera nota, Walsh hizo explícita la reticencia intencional del texto. Encontramos un fragmento que lo ilustra claramente: "En la madrugada del 13 de mayo, un hombre que llamaremos N.N. se levantó con rabia en el centro de La Real" (Walsh 1968a: 2). En la segunda nota hallamos un mecanismo 
típico de la creación de intriga: la mención de un hecho del cual se hablará más adelante. "Su nombre verdadero era Domingo Blajaquis y fue uno de los muertos olvidados de esa noche. Ya hablaremos de él, lo que haya quedado de su historia novelesca" (Walsh 1968b: 6). En el paratexto de la tercera nota (un croquis que reproduce la ubicación de los involucrados en el tiroteo) Walsh escribe:

Una $\mathrm{x}$ señala los asientos ocupados por las personas que aún no han declarado ante el juez. Cuando comenzó el tiroteo había un hombre de pie y también lo hemos señalado con una X. En los próximos números esperamos despejar estas incógnitas. (Walsh 1968c: 6)

Al pie del paratexto de la cuarta nota (otro croquis) se lee:

En el próximo número publicaremos las iniciales de este tirador, y le haremos la invitación de práctica para que hable por su cuenta. Las restantes iniciales y números en el grupo vandorista corresponden a Barreiro y a los "desconocidos" cuya identidad iremos revelando escalonadamente. (Walsh 1968d: 6)

Esta frase explicita la deliberada reticencia del texto. Al instar a los "desconocidos" a declarar en la nota 3, Walsh lo hace de modo colectivo. Ninguno de ellos responde. En la siguiente nota focaliza la interpelación en J.P y advierte que los nombres de los vandoristas serán revelados por etapas (lo cual efectivamente sucedió). Walsh obtendría una respuesta recién un año más tarde, cuando la investigación fue publicada en forma de libro. La misma no vendría de parte de Vandor, sino del sindicalista Miguel Gazzera, que calificó los crímenes como un "doloroso suceso protagonizado por peronistas" (Dawyd 2012: 96), dejando así en claro que un sector del sindicalismo argentino conceptualizaba lo sucedido de un modo que -en sus presupuestos fundamentales- guardaba una importante similitud con las categorías de análisis utilizadas por La Prensa.

\section{Palabras finales}

1968 es un año clave en la vida de Walsh por dos motivos muy diferentes: comienza a trabajar en la CGT de los Argentinos y firma un contrato para publicar una novela de ficción. La novela quedará sin publicar. Otros escritos de ficción inéditos serían secuestrados por los militares que allanaron su domicilio en marzo de 1977 luego de asesinarlo y hacer desaparecer su cadáver. Al día de hoy se ignora si estos textos fueron destruidos o aún están en poder de desconocidos.

Creemos que las notas sobre el tiroteo de La Real pueden leerse como una respuesta anticipada a interrogantes teóricos que el autor desarrollaría fundamentalmente a partir del año 1969, en tanto la escritura de las mismas implica una toma de posición en el debate político-literario de la época. Lo primero que advertimos es la opción por la novela: el carácter de los mismos hechos a investigar -así como también sus propios objetivos políticos- lo obligan a recurrir al género como matriz discursiva. La experiencia de publicación de las notas complejiza asimismo la dicotomía factográfica entre el libro y el periódico: vemos aquí una experiencia de continuidad en la que la investigación publicada en el semanario culmina con la reproducción del primer capítulo del libro. El montaje de Walsh se radicaliza y pasa por alto las taxonomías y dicotomías del pensamiento de la época: los discursos que convoca ¿Quién mató a Rosendo? están en tensión con sus propias convenciones y con la temporalidad que los rige. Estamos ante un folletín mediático "sin noticia", que a fin de reactualizar el caso recurre a los esquemas narrativos de la novela de suspenso y asume asimismo los principios de discontinuidad y montaje característicos de la vanguardia (en este sentido, el análisis de los paratextos de las notas merece en sí mismo un artículo aparte). Consideramos que el hecho de que sean solo ocho notas no invalida nuestra taxonomía: se trata de una novela por entregas cuya extensión asume las críticas de la factografía y por lo tanto se corresponde con la temporalidad política del momento (la última de las notas de la serie es el primer capítulo del libro, que se publica en vísperas del Cordobazo).

Por todo lo dicho, leemos esta investigación como un texto de altísima complejidad, escrito bajo el peligro y la urgencia de la coyuntura política, que el autor introduce en la trama como uno de sus motores discursivos. Un texto abierto a los avatares más difíciles de su presente y que lleva desde sus mismas condiciones de producción la impronta de la interlocución obrera, que obligó a su autor a replantear los modos de narrar. Así lo recuerda el Indio Allende, un militante gráfico que formó parte de la CGT de los Argentinos y de las Fuerzas Armadas Peronistas: 
¿Vos leíste esa obra Un kilo de oro? Bueno, imaginate que sea durísimamente criticada por nosotros. Entonces cuando él quiere sacar su publicación sobre lo de La Real -toma aire y habla como si volviera a hablarle a Walsh-: No te zarpés, no te vengás a hacer el pelotudo, que esta obra tiene que ser dirigida a nuestra gente, flaco, si no no te vamos a dar los datos... (Arrosagaray 2006: 67)

La escritura de ¿Quién mató a Rosendo? se revela así como un producto de negociación con los militantes, que desde el principio impusieron sus condiciones para colaborar con la investigación. Pero esto no es todo: Walsh contó con la participación de los sobrevivientes en algunas tareas propiamente periodísticas (tal es el caso del reportaje a Norberto Imbelloni, que realizó en compañía de Rolando Villaflor). Vemos aquí un claro signo de época: los sectores subalternos devienen interlocutores con capacidad de impugnar los textos que dan cuenta de ellos. Aquí el otro no solo es hablado: también habla. ¿Quién mató a Rosendo? es un producto indisociable de la interlocución obrera y de la experiencia política de dos sujetos distintos unidos por una lucha en común. De ese problemático "nosotros" también da cuenta este texto.

\section{Referencias bibliográficas}

Arrosagaray, Enrique (2006). Rodolfo Walsh, de dramaturgo a guerrillero. Buenos Aires: Catálogos.

Benjamin, Walter (1975), "El autor como productor", en Tentativas sobre Brecht. Iluminaciones III, Madrid; Taurus, pp. 117-134.

Benjamin, Walter (2007), "La obra de arte en la época de su reproductividad técnica", en Conceptos de filosofía de la historia. Buenos Aires: Terramar Ediciones, pp.147-182.

Benjamin, Walter (2014). Calle de mano única. Buenos Aires: El Cuenco de Plata.

Baroni, Raphaël (2002), "Incomplétudes stratégiques du discours littéraire et tension dramatique", Littérature, no 127 , septiembre de 2002, pp. 105-127.

Barthes, Roland (2003), "Estructura del suceso", en Ensayos críticos. Buenos Aires: Grupo Editorial Planeta/Seix Barral, pp. 259-272.

Brik, Ossip (1987a), "Plus près du fait", en Gérard Conio. Le constructivisme russe. Tome II: Le constructivisme littéraire". Lausanne : L'Age de l'Homme, pp.182-185.

Brik, Ossip (1987b), "Contre la personnalité créatrice" en Gérard Conio. Le constructivisme russe. Tome II: Le constructivisme littéraire. Lausanne : L’Age de l'Homme, pp. 186-188.

Brik, Ossip (1987c), "Le déclin du sujet", en Gérard Conio. Le constructivisme russe. Tome II: Le constructivisme littéraire. Lausanne : L'Age de l'Homme, pp. 189-190.

Brik, Ossip (1987d), "Former les écrivains", en Gérard Conio. Le constructivisme russe. Tome II: Le constructivisme littéraire. Lausanne: L'Age de l'Homme, pp. 195-198.

Bourdieu, Pierre (1991). El sentido práctico. Madrid: Taurus.

Chuzhak, Nikolai (2006), "A Writer's Handbook", October, n 118, otoño de 2006, pp. 78-94.

Dawyd, Darío (2012), "Del semanario al libro. La escritura del Rosendo de Rodolfo Walsh como construcción del vandorismo en la Argentina del peronismo fracturado", Trabajo y Sociedad, Vol. 15, n 18, verano de 2012, pp. 87102.

Del Río, Víctor (2010). Factografía. Vanguardia y comunicación de masas. Madrid: Abada Editores.

Garand, Dominique (1998), "Propositions méthodologiques pour l'étude du polémique", en Dominique Garand y Anne Hayward. États du polémique. Québec: Éditions Nota Bene, pp. 211-268.

Gramsci, Antonio (1998). Cuadernos de la cárcel: literatura y vida nacional. México: Distrito Federal, Juan Pablos Editor.

(1996)[1969], “¿Lobo estás?”, Siete Días, no 110, 16 de junio. En Rodolfo Walsh. Ese hombre y otros papeles personales. Buenos Aires: Seix Barral, pp. 115-121.

Lukács, Georg (1966). Problemas del realismo. México: Fondo de Cultura Económica.

Mestman, Mariano (1997), "Semanario CGT. Rodolfo Walsh, periodismo y clase obrera", Revista Causas y Azares, $\mathrm{n}^{\circ}$ 6, primavera de 1977, pp. 193-208.

Piglia, Ricardo (1996)[1973], "Hoy es imposible en Argentina hacer literatura desvinculada de la política”, en Rodolfo Walsh. Ese hombre y otros papeles personales. Buenos Aires: Seix Barral, pp. 213-225.

Revaz, Françoise, Stéphanie Pahus y Raphaël Baroni (2007) "Classer les 'récits' médiatiques : entre narrations ponctuelles et narrations sérielles", en Abdelahad Chraibi (dir.). Classer les récits. Théories et pratiques. Paris : L'Harmattan, pp. 59-82.

Revaz, Françoise y Raphaël Baroni (2007), "Le fait divers sérialisé, un feuilleton médiatique", Les Cahiers du journalisme, nº 17, verano de 2007, pp. 194-209. 
Revaz, Françoise (2008), “Analyse (trans) textuelle d'un objet discursif complexe: le feuilleton journalistique”, en Jacques Durand, Benoît Habert y Bernard Laks. Congrès mondial de linguistique française. Paris : EDP Sciences, pp. $1417-1428$.

(1968), "Semanario: pro y contra", Semanario CGT, n 15, 8 de agosto, p.4.

Tarsitano, Carlos (1972), "Narrativa y país real. Testimonios de Rodolfo Walsh y Miguel Briante", La Opiníon: Suplemento Cultural, 11 de junio de 1972, pp. 6-7.

Todorov, Tzvetan (1992), "Tipología del relato policial”, en Daniel Link (comp.) El juego de los cautos. La literatura policial, de Poe al caso Giubileo. Buenos Aires: La Marca, pp. 46-51.

Tretiakov, Sergei (2006a), “The New Leo Tolstoy”, October, $\mathrm{n}^{\mathrm{o}}$ 118, otoño de 2006, pp. 45-50.

Tretiakov, Sergei (2006b), "To Be Continued", October, n 118, otoño de 2006, pp. 51-56.

Tretiakov, Sergei (2006c), "The Biography of the Object”, October, no 118, otoño de 2006, pp. 57-62.

Tretiakov, Sergei (2006d), "The Writer and the Socialist Village”, October, n 118, otoño de 2006, pp. 63-70.

(1968), "Un corresponsal en cada fábrica", Semanario CGT, nº 12, 18 de julio, p. 6.

Walsh, Rodolfo (1968a), “¿Quién mató a Rosendo? Primera nota”, Semanario CGT, nº 3, 16 de mayo de 1968 , p.2.

Walsh, Rodolfo (1968b), “QQuién mató a Rosendo? Segunda nota”, Semanario CGT, nº 4, 23 de mayo de 1968 , p. 6.

Walsh, Rodolfo (1968c), “¿Quién mató a Rosendo? Tercera nota”, Semanario CGT, nº 5, 30 de mayo de 1968 , p 6.

Walsh, Rodolfo (1968d), “¿Quién mató a Rosendo? Cuarta nota”, Semanario CGT, nº 6, 6 de junio de 1968, p. 6.

Walsh, Rodolfo (1968e), “¿Quién mató a Rosendo? Quinta nota”, Semanario CGT, nº 7, 13 de junio de 1968 , p. 6.

Walsh, Rodolfo (1968f), “¿Quién mató a Rosendo? Sexta nota”, Semanario CGT, nº 8, 20 de junio de 1968 , p. 5.

Walsh, Rodolfo (1968g), “¿Quién mató a Rosendo? Última nota”, Semanario CGT, nº 9, 27 de junio de 1968 , p. 6.

Walsh, Rodolfo (1969), “¿Qué es el vandorismo?”, Semanario CGT, nº 45, 22 de mayo de 1969, p. 4.

Walsh, Rodolfo (1996). Ese hombre y otros papeles personales. Buenos Aires: Seix Barral.

Walsh, Rodolfo (2001). Operación Masacre. Buenos Aires: Clarín, La Biblioteca Argentina.

Walsh, Rodolfo (2003). ¿Quién mató a Rosendo? Buenos Aires: Ediciones de la Flor. 